\title{
Intentionality of the Design Through the Redesign: Albanese House by Leone and Culotta
}

Manuela Milone

Abstract

Albanese house was designed in 1982 and takes its name from the one who commissioned the project from the studio of Culotta and Leone. The achievements of the study were studied, focusing in particular on the various projects related to single-family houses.

Given the technological characteristics of the project, an analysis of the international context was also necessary, in particular the suggestions of the shingle style cottages were studied.

In addition, the construction technology underlying the project, or the balloon frame, typical of the US context, was also studied.

The project shows great attention to the exhibition, and to the relationship between inside and outside. The whole project is in perfect harmony with the context in which it fits.

Vectorization of drawings, applications of the 3D model, photo insertion and technological analysis which allowed a sufficient level of knowledge of the architectural project.

However, by analyzing the project drawings and dwelling on the details, several issues emerged which, certainly due to the absence of an executive phase of the design, remained unexplored.

Keywords

redesign, Cefalù, graphic representation.

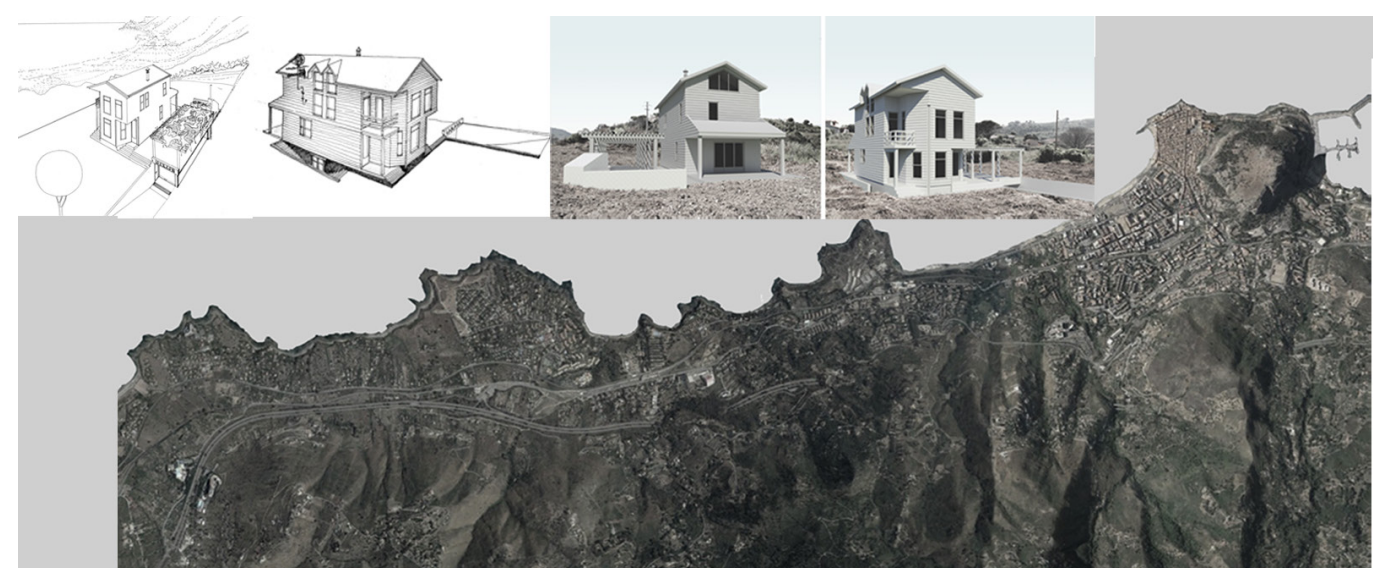




\section{Introduction}

The genesis of the Albanese house (figs. I , 2) project was influenced by two important factors. The first of these is linked to the request by the client, Mr. Albanese, owner of a carpentry shop, to build a building using a construction technique that made use of wood. The second factor was the trip to America that Pasquale Culotta and Giuseppe Leone made in 1978, a couple of years before they were entrusted with the design task in 1982. The travel to America gave the two designers different suggestions and design ideas, in particular the study of the projects by Robert Venturi, John Rauch and Denise Scott Brown, for the Trubek house and the Wislocki house was the starting point for developing the project. The resulting project was that of an American cottage-style house, to be built with a balloon frame construction system.

Access to the project site takes place from the small dirt road of street Monte.

We are in one of the highest points of the Monte district; although we are in the countryside, the presence of the sea is dominant. From east to west, passing through the north, it is before our eyes. A presence so important that it becomes part of the project.

It is no coincidence that the largest windows of the house are on the north elevation, in the direction of the sea, while in the south, the direction that enjoys a worse panoramic view, we find only the indispensable windows.

Fig. I. Wislocki house (left) and Trubek house (right).

Fig. 2. Wislocki house: first plan and elevation (left); Trubek House: first plan and elevation (right).

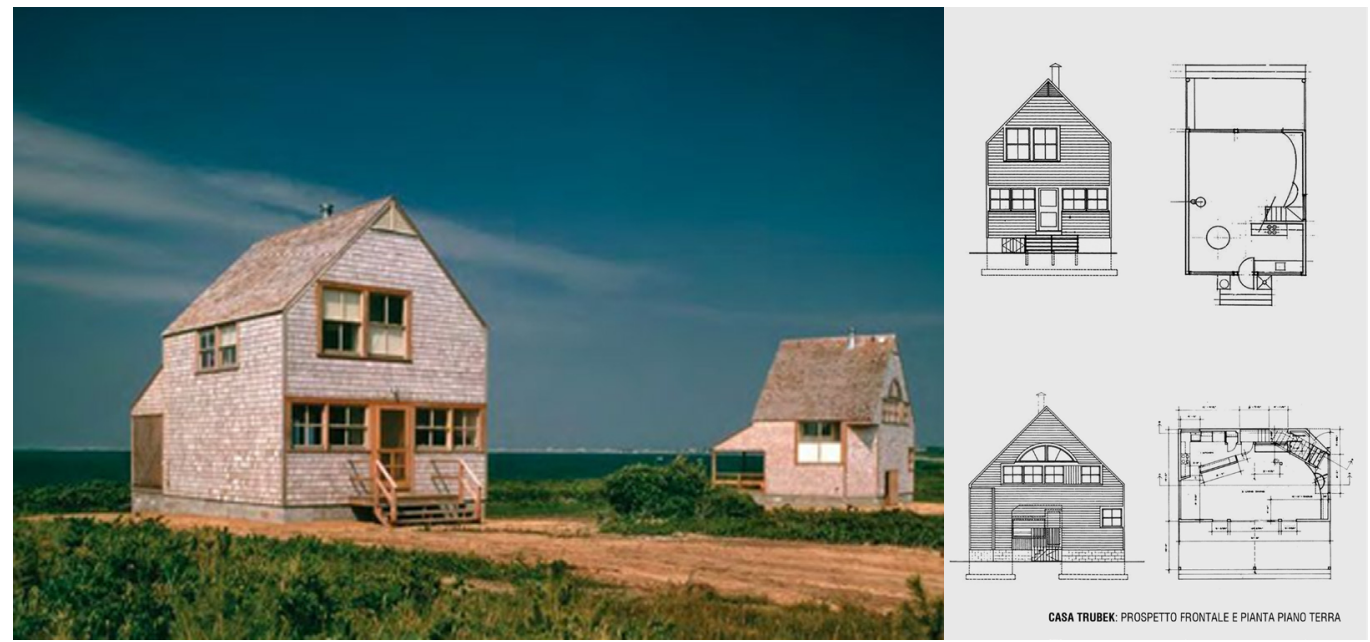

\section{The project}

Access to the house is via two symmetrical doors on the west elevation (figs. 3, 4). The ground floor of the Albanese house consists of a single space used as a kitchen in the rear and a living room in the front. The living room located in the part closest to the entrance, is arranged inside a bow-window, while the dining area is located in the central part of the room, in correspondence with the fireplace.

Through a large opening from the kitchen you access a veranda that favors the relationship between the interior and exterior. Thanks to a single ramp staircase located on the south wall, you enter the first floor. As soon as we reach the first floor we can choose whether to continue towards the second staircase of the house that leads us to the second floor, or turn towards the balcony and go to the two bedrooms, both with private bathroom. The landing also leads to a small balcony, built on the roof of the veranda on the ground floor, which turns its gaze towards the Cefalù countryside.

Once on the second floor we immediately perceive the presence of the double-pitched roof. The height at the eaves of this floor is only $2.60 \mathrm{~m}$, therefore the net light of the floor is very low. 
A small corridor takes us to two symmetrical bedrooms, while at the bottom of the house there is a large bathroom.

The interiors are made using every minimal space. Where the occasion arose, built-in wardrobes and storage units were quickly inserted.

As for the exteriors, in addition to the veranda, on the elevation overlooking the street monte there is a pergola of a length equal to the entire building.

Below it, the project involved the construction of a brick barbecue corner, as well as an oven. The entire shape of the building, including the part with a pergola roof, covers a large cellar floor.

It can be accessed from many sides. The main entrance is also suitable for vehicles; therefore it has a large ramp. The other entrance on the basement floor is located on the north front. A double flight of stairs leads us to the lower level.

The last access is instead inside the house, via a staircase corresponding to the one that leads from the ground floor to the first.

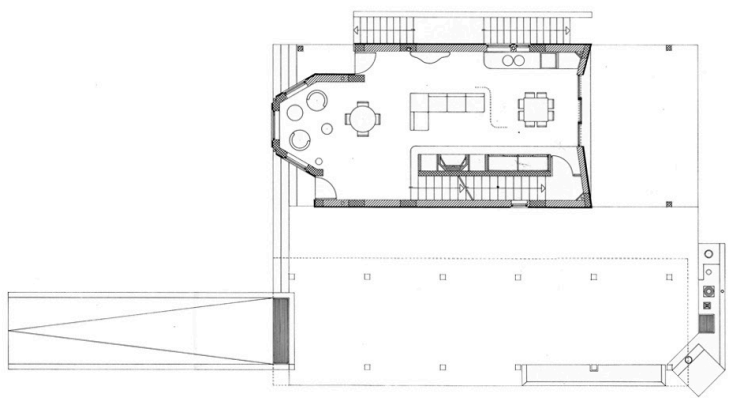

PAANTA PANO TERRA
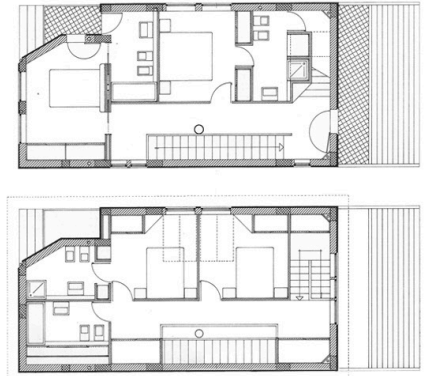

PIANTE PIANO PRIMOE SECONDO
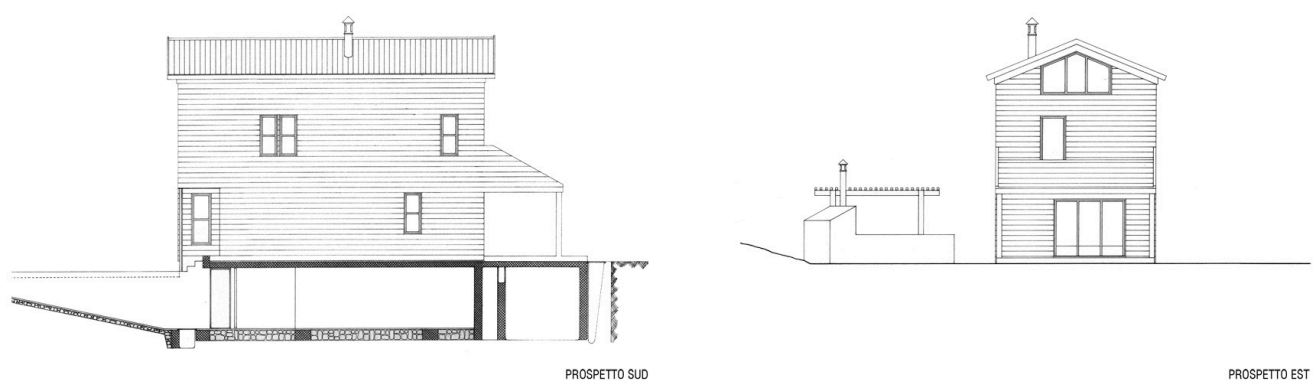

Fig. 4. Albanese house: elevations.
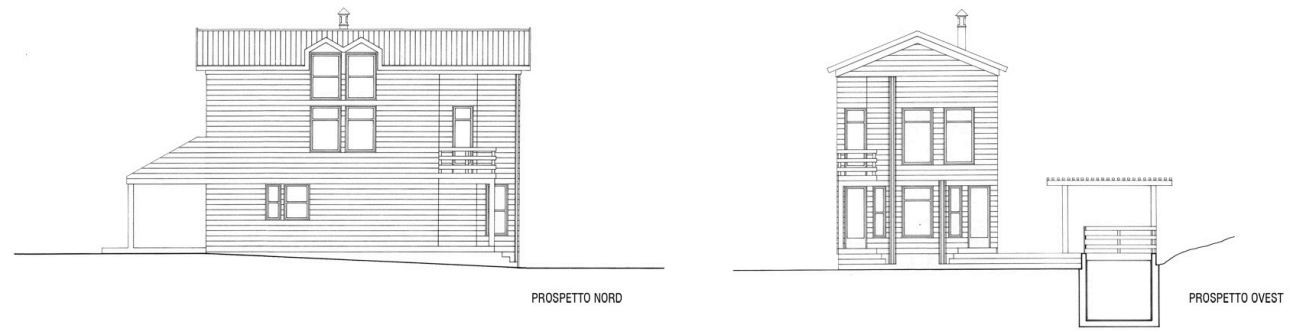


\section{The building system}

The construction system (fig. 5) used in the project is that of the balloon frame. A wooden structure, typical of American cottages.

The Albanese house project, while not giving us detailed construction details, gives us clear indications on what the structure underpinning the building was.

The base unlike most of the rest of the structure is in reinforced concrete. In the cellar floor, in fact, we find a framed system consisting of beams, pillars and partitions in reinforced concrete. In addition to the basement floor, with this construction system stairs are created that lead to the ground floor and the perimeter gap.

The structure on the upper floors changes radically; it is in fact made entirely of wood. This wooden structure starts from the ground floor, where the pillars are anchored to the base. In the first level, at the node between the pillar of the ground floor and that of the first floor, the beams are grafted, using a triple knot system. The same operation is repeated in the nodes between the first and second floors, and in the nodes that tie the roof. The floors, made using the same construction system, are made up of joists which, by grafting into the main beams, provide a dense structure, above which slats of a smaller size are inserted, on which the floor boarding will be fixed.

The perimeter walls, in addition to the classic coffered grid characteristic of the balloon frame, have a double coating both inside and outside. The external one is made up of three different layers. An insulating layer, a thin sheath, and a finishing layer. It is composed of a system of boards linked together by an interlocking system. The tables, placed in the longitudinal direction, as well as acting as additional thermal insulation, horizontally marked the facades of the building, giving it the typical appearance of shingle-style cottages.

The pitched roof, made using the same technique, brings rainwater into an internal gutter channel, from which it will be poured into drainpipes inserted in the wall package.

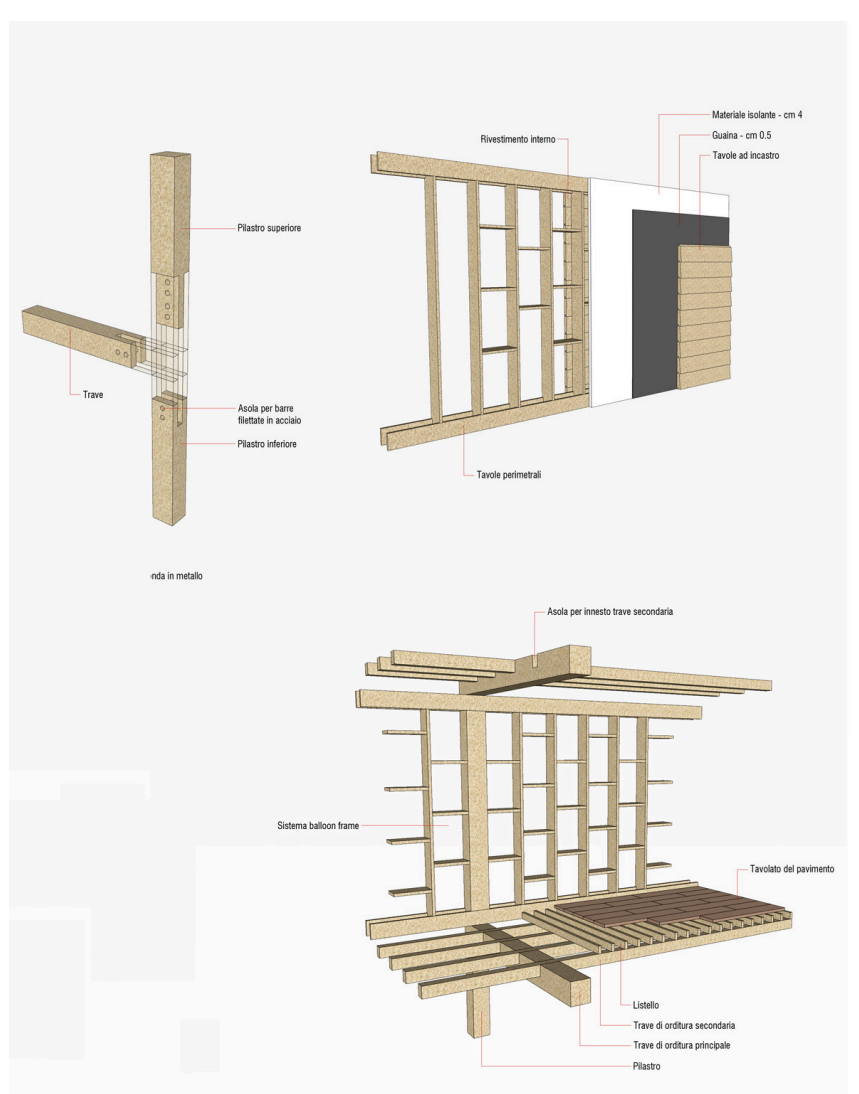




\section{The perspective restitution}

Through the perspective restitution we can go back to the geometric shape, represented in its exact proportions, of an object whose representation we have in perspective (figs. 6-8). One of the first applications of this technique was that of terrestrial photogrammetric survey for the production of the cartography of the territory.

Nowadays, for this field, various software have been developed that automate the work, and therefore make its use superfluous.

However, the perspective restitution remains a valid aid for architectural survey operations. In particular, it proves to be particularly useful for tracing, through the application on a photograph, the geometric shape of the elevations of the buildings.

The elements that make up the technique are the same as for perspective, as anticipated it is the reverse operation.

Through the prospective restitution, in fact, we can go back to the point of view, its distance from the picture, and identify the land line.

In the specific case of this degree thesis, the application of the prospective restitution was useful in order to verify the correct proportionality of the perspectives present among the original project designs of the Albanese house.

In particular, in the first it was assessed whether there was a correct proportionality in the base plan, while in the second it was decided to evaluate whether the north elevation had been built according to the geometric rules, or if it had been emphasized to facilitate a reading of the horizontal scan.

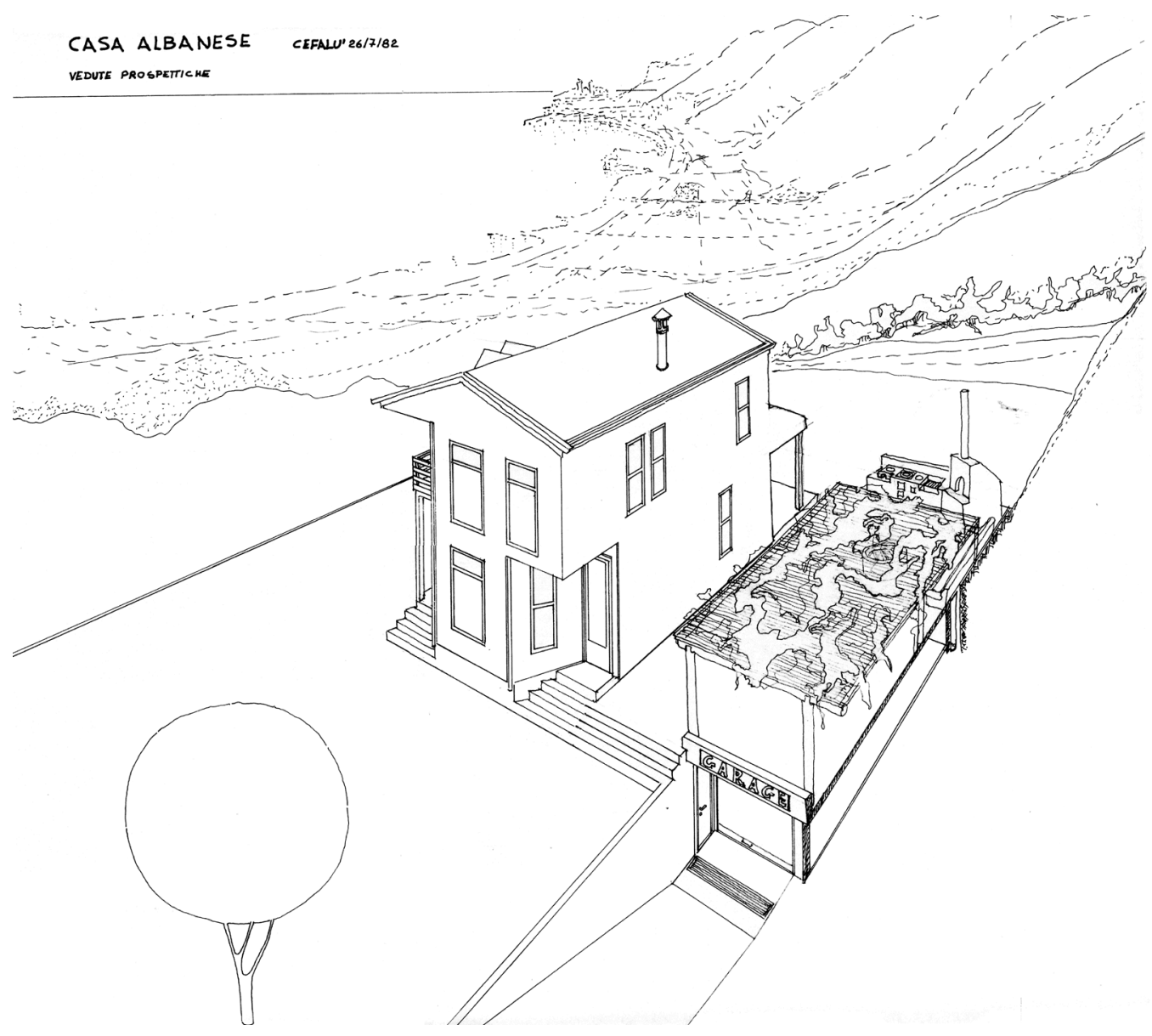




\section{Southwest perspective}

The design in question was created using an accidental perspective, with a vertical framework.

The first, almost immediate, approach was to identify the two vanishing points FI and F2, which once joined returned the horizon.

The perspective was also complete with the horizontal line, therefore the geometric identification of the latter was only useful in order to confirm the accuracy of its representation. Secondly, the observer's point of view was identified, taking advantage of one of the two diagonals in addition to the two main directions.

By tracing two circumference arcs with center respectively in FI and F2, and amplitude equal to the distance of them from the point of view, the two measuring points $M I$ and $M 2$ have been identified on the horizon line.

Note the two vanishing points, the point of view and the measurement points, in order to proceed with the prospective restitution it was necessary to identify the land line.

To do this, two different techniques were used, which however identified the same position of the land line. Since the dimensions of the architectural artefact were known, it was possible to use the length of the base side to obtain the ground line from the measurement point. The position of the aforementioned land line was also calculated again using the actual height of the building, known to us.

This procedure confirmed the previous position, therefore it was possible to confirm this position.

At this point it was possible to proceed with the prospective restitution.

The resulting rectangle had a ratio between the length of the two sides equal to the ratio of the actual lengths in plan, therefore the initial hypothesis was verified.

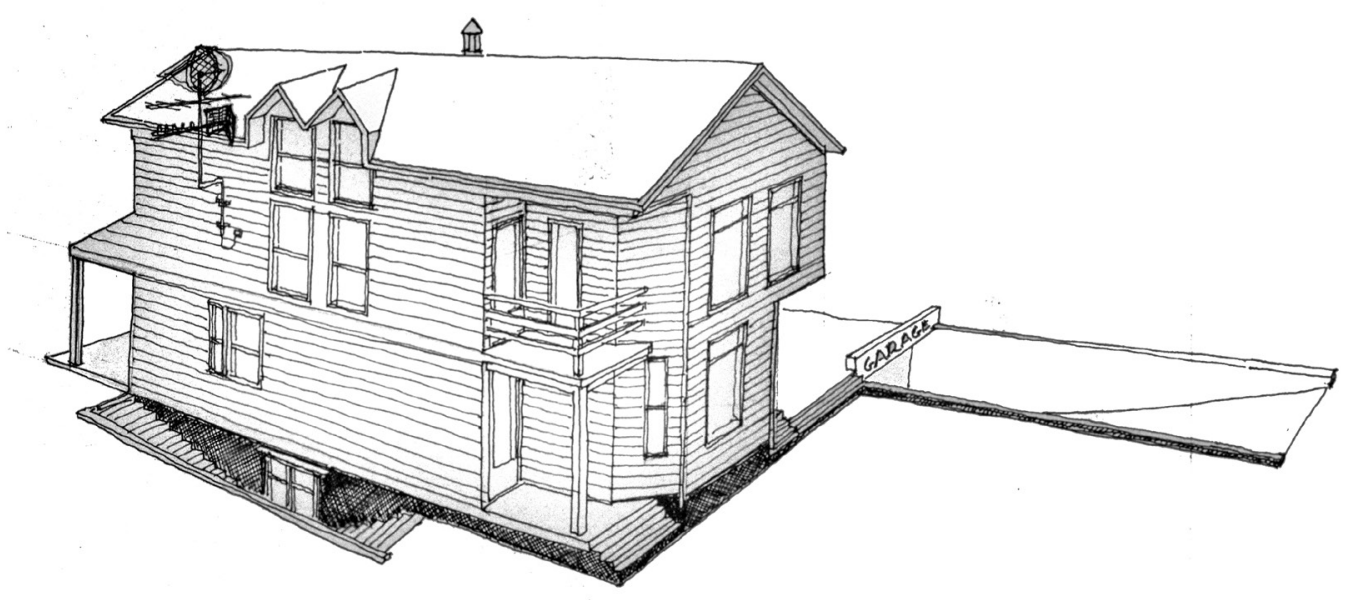




\section{Northwest perspective}

The second perspective restitution concerned the perspective with a north-west view. As in the previous case, it is an accidental perspective with a vertical picture, however it appears less detailed and totally without context.

The hypothesis to be verified is that the proportions between the north elevation of the perspective and that of the project drawings corresponded.

We proceeded with a technique similar to that used previously to identify the land line, the horizon line and the point of view. The restitution was made by identifying the straight lines whose direction is identified by the junction of the measuring points passing through the measuring points $\mathrm{MI}$ and $\mathrm{M} 2$, with the vertices of the rectangle in which the outline of the prospect is entered. Once these positions were identified, they were prolonged until the ground line was identified, and the outline of the elevation was built on it. In this case the initial hypothesis has not been verified, in fact the studied perspective shows a more squat prospect than the real one. This data however confirms the hypothesis that the designers wanted to give more emphasis to a longitudinal scan of the building.
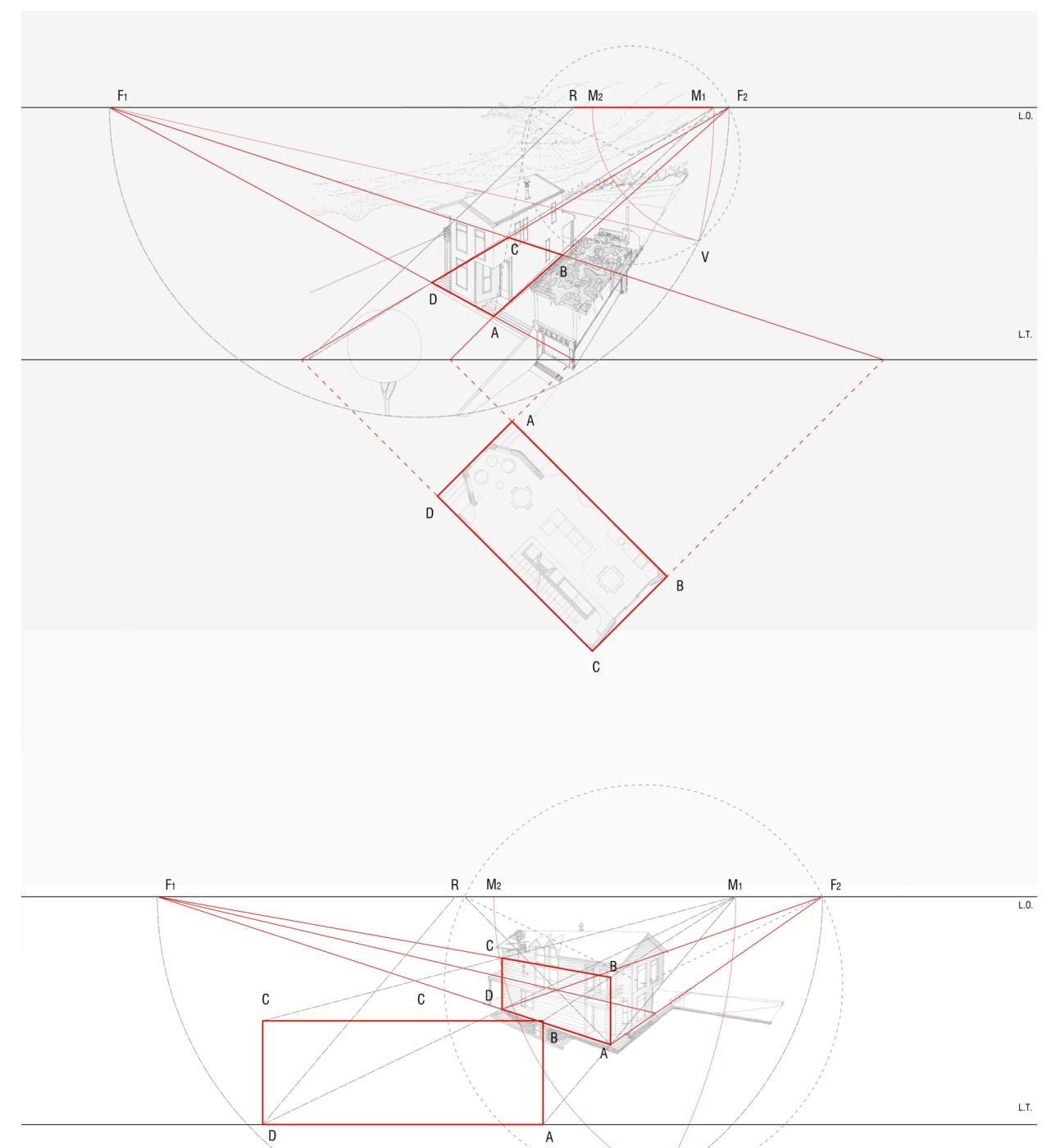


\section{The realization of the $2 \mathrm{~d}$ and $3 \mathrm{~d}$ model}

The first step for a correct digital representation was to convert the paper drawings into image files. High resolution scans were carried out and the files thus obtained were punched in order to eliminate any imperfections and align the horizontal and vertical lines of the drawings with the exact position.

The next step is to vectorize the previously processed scans using CAD software.

This made it possible to obtain vector images, or images that can be scaled to infinity without any loss of quality, which is very useful for better studying all the smallest details at the appropriate scales.

The Google SketchUp Pro software was used to create the three-dimensional model of Mr. Albanese's house. By importing the 2D plans created earlier, the entire building was recreated.The model created consists of four blocks, one on each floor, including the cellar. Furthermore, an abacus of the fixtures has been created from which to draw when necessary.

A further block was created to model pitched roofs, including also the two niches for the attic windows.

Finally, the horizontal finishing board of the elevations was modeled.

Fig. 9. Perspective sections.
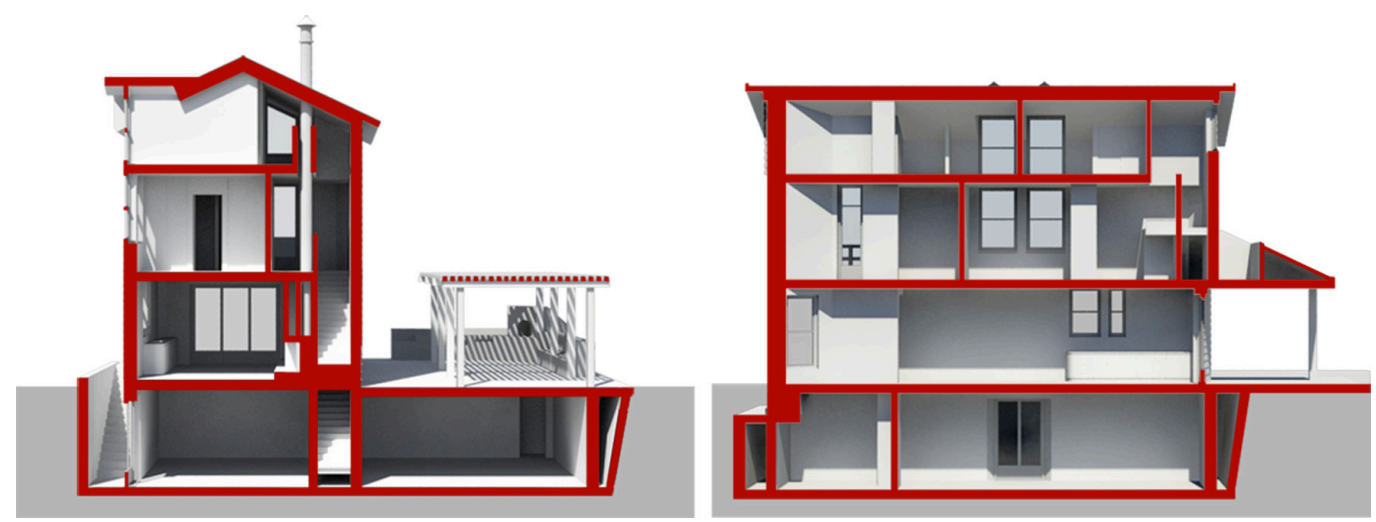

\section{Applications of the 3D model}

The first operation performed with the model was a study of the shadows. By imposing a $45^{\circ}$ light source, the shadows were exported to act as an aid to their geometric construction in the CAD software (figs. 9, 10).

Secondly, the model created on SketchUp was exported so that it could be imported from the Autodesk 3D Studio Max software and renderings could be made.

Once the model was imported, the materials were applied. Since there was neither a descriptive technical report nor any construction detail, it was not possible to create a photorealistic model, and therefore only one white material was used for the whole model, except for the glass.

Before rendering the lights were applied to the various views. In this specific case, MrSun and MrSky were used, two tools integrated in the MentalRay rendering engine that allow you to simulate sunlight faithfully.

The next step was to produce views. Once the observation points were identified, cameras were inserted, and their inclination and focal distance were adjusted.

After that the building was rendered in all necessary perspectives.

Through photo-insertion, it was possible to insert the unrealized building within its original context, thus allowing to evaluate the overall effect of the work in the context for which it is intended. 
The first step is to collect the photos. High-quality photographs should be taken including both large amounts of context and macro details. Once the necessary photographs are obtained, the previously created rendering can be superimposed, paying attention to the exact correspondence between the focal length and the position of the camera in the photo, with respect to those of the rendering.

To allow a better graphic rendering, the photos of the place have undergone a partial desaturation, such as to make them chromatically corresponding to the three-dimensional single material model.

\section{Conclusion}

Analyzing the project drawings and dwelling on the details, several issues emerged which, certainly due to the absence of an executive phase of the design, remained unexplored (fig. II).

One of the themes that has certainly remained unexplored is that of the structural system. Although it is clear what the design choice was, this does not appear as clear in the drawings. Probably a scale of greater detail would have clarified the stratigraphy of both the floors and the perimeter walls.

In order to hypothesize which system was used, reference was made to other Leone and Culotta projects. Including some sketches of construction details and a balloon frame structure, which given the temporal proximity between the two projects, can be assumed to be compatible.
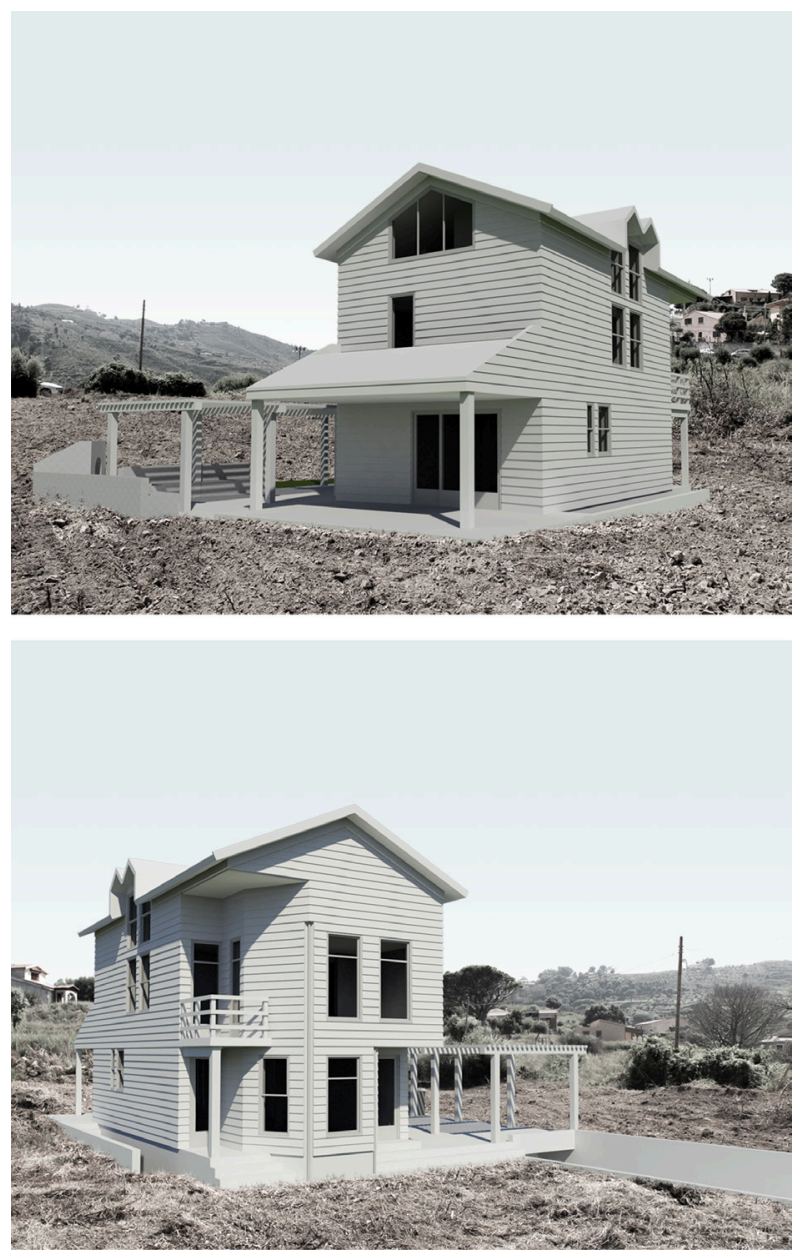
A further aspect which has remained unexplored is that of the arrangement of the external spaces. It is enough to observe all the projects of Culotta and Leone, to understand that the attention to the context and the external spaces was something important. Each project is made up of horizontal and vertical paths that indissolubly link the project to the place; all this at Albanese house does not happen. It seems difficult to think that this house was not in any way linked to the place where it is located, and more correct to believe that the study of the external space has remained unexplored.

Even the exact location within the lot can be cataloged among the aspects that would have been necessary to deepen. The only reference that has come down to us is a perspective view detailed enough to define the exact position in which the architectural artefact would have been found with little approximation. In fact, it is located in the only point in the Monte district that turns its gaze towards the sea.
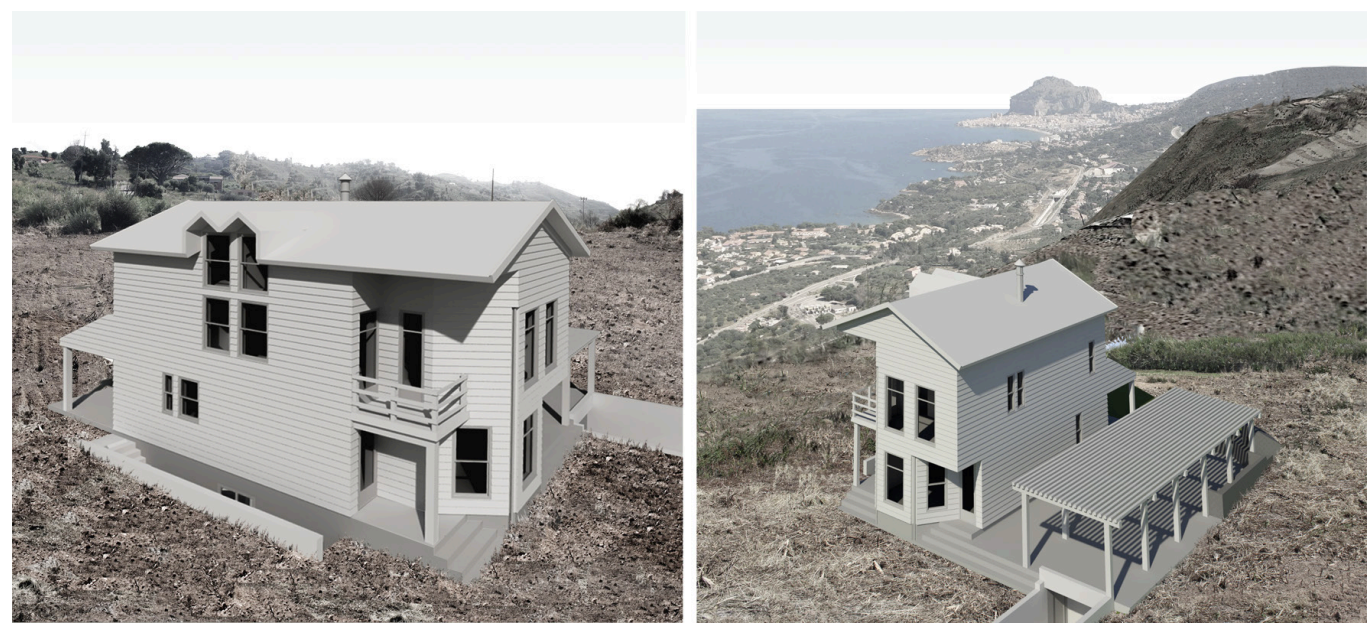

\section{References}

Biancucci Antonio (20 I0). II progetto necessario. Pasquale Culotta e il giornale della progettazione in Architettura (1979-1993). Palermo: Edizioni di Passaggio.

Culotta Pasquale, Leone Giuseppe (1985). Le occasioni del progetto. Cefalù: Edizioni della Medina.

Curtis William J. (1999). L'architettura moderna dal 1900. Londra: Phaidon.

Fano Gaetano (1979). La restituzione prospettica da prospettiva razionale. Bari: Dedalo Libri.

Morgan Beth, Roth Lelan M. (1999). Shingle Styles. Innovation and Tradition in American Architecture 1874 to 1982. New York: Harry N. Habrams.

Panzarella Marcello (20।3). Culotta e Leone a Cefalù. Le case unifamiliari. Geraci Siculo: Edizioni Arianna.

Scully Vincent (200I). The shingle style today of the historian's revenge. New York: Ed. George Braziller.

Von Moss Stanislaus (1987). Venturi Rauch \& Scott Brown. Building and Projects. Milano: Rizzoli.

Author

Manuela Milone, Università di Palermo, manuela.milone@unipa.it

To cite this chapter. Milone Manuela (2020). Intentionality of the design through the redesign: Albanese house by Leone and Culotta. In Arena A., Arena M., Brandolino R.G., Colistra D., Ginex G., Mediati D., Nucifora S., Raffa P. (a cura di). Connettere. Un disegno per annodare e tessere. Atti del $42^{\circ}$ Convegno Internazionale dei Docenti delle Discipline della Rappresentazione/Connecting. Drawing for weaving relationships. Proceedings of the 42th International Conference of Representation Disciplines Teachers. Milano: FrancoAngeli, pp. 2458-2467. 